\title{
Sickness absence in hospital physicians: 2 year follow up study on determinants
}

\author{
M Kivimäki, R Sutinen, M Elovainio, J Vahtera, K Räsänen, S Töyry, J E Ferrie, \\ J Firth-Cozens
}

University of Helsinki, Department of

Psychology, Division of Applied Psychology,

PO Box 13, FIN-00014

University of Helsinki,

Finland

M Kivimäki

Vaasa Central

Hospital, Vaasa,

Finland

R Sutinen

National Research and Development Centre for Welfare and Health, Helsinki, Finland

M Elovainio

Finnish Institute of Occupational Health, Helsinki, Turku and Kuopio, Finland

M Kivimäki

J Vahtera

K Räsänen

S Töyry

University College London Medical School, London, UK J E Ferrie

University of Northumbria at Newcastle, Newcastle upon Tyne, UK

J Firth-Cozens

Correspondence to: Dr M Kivimäki

mika.kivimaki@occuphealth. Accepted 9 February 2001

\begin{abstract}
Objectives-To identify determinants of sickness absence in hospital physicians. Methods-The Poisson regression analyses of short (1-3 days) and long ( $>3$ days) recorded spells of sickness absence relating to potential determinants of sickness absence were based on a 2 year follow up period and cohorts of 447 (251 male and 196 female) physicians and 466 controls (female head nurses and ward sisters).

Results-There were no differences in health outcomes, self rated health status, prevalence of chronic illness, and being a case on the general health questionnaire (GHQ), between the groups but physicians took one third to a half the sick leave of controls. All the health outcomes were strongly associated with sickness absence in both groups. Of work related factors, teamwork had the greatest effect on sickness absence in physicians but not in the controls. Physicians working in poorly functioning teams were at 1.8 (95\% confidence interval $(95 \% \mathrm{CI}) 1.3$ to 3.0$)$ times greater risk of taking long spells than physicians working in well functioning teams. Risks related to overload, heavy on call responsibility, poor job control, social circumstances outside the workplace, and health behaviours were smaller.

Conclusion-This is the first study of hospital physicians to show the association between recorded sickness absence and factors across various areas of life. In this occupational group, sickness absence is strongly associated with health problems, and the threshold for taking sick leave is high. Poor teamwork seems to contribute to the sickness absenteeism of hospital physicians even more than traditional psychosocial risks-such as overload and low job control. These findings may have implications for training and health promotion in hospitals.

(Occup Environ Med 2001;58:361-366)
\end{abstract}

Keywords: health care personnel; occupational health; psychosocial factors

Sickness absence is important as a measure of wellbeing and as a cause of lost productivity. Health, behavioural risks, and stress have predicted sickness absence in various occupational groups ${ }^{12}$ but studies specifically on physicians remain scarce. ${ }^{3-5}$

The most commonly reported sources of stress in physicians are overload (feeling overloaded, amount of overwork, and time on call) and poor job control. ${ }^{4-8}$ However, it has been suggested that overload may partly reflect the quality of teamwork that the physicians experience. ${ }^{9}$ Also, social circumstances, social support, and life events outside the workplace have contributed to stress in physicians. ${ }^{6}$ Other factors reported to be associated with stress in this occupational group include dealing with patients' suffering, death, emergencies, complaints and litigation, being poorly managed or resourced, and personality traits-such as a high level of self criticism (Karasek, personal communication). ${ }^{610}$

Scientific literature on physicians is based on self reported sickness absence, ${ }^{3-5}$ a measure which is vulnerable to reactivity and recall problems, and testing of the determinants of sickness absence has been limited to demographic factors. The present study on hospital physicians examined the extent to which factors related to health, work, and social circumstances are associated with recorded sickness absence.

\section{Methods}

STUDY POPULATION

In Finland, each municipality, alone or in federation with other municipalities, organises hospital care for its inhabitants. This study was carried out in three hospital districts (Varsinais-Suomi, Kanta-Häme, and Vaasa) participating in a larger project "hospital personnel and health" coordinated by the Finnish Institute of Occupational Health. There was one university teaching hospital, two central hospitals, and eight regional hospitals providing specialised care for 780000 inhabitants ( $15 \%$ of the total Finnish population).

A questionnaire, a covering letter explaining that responses will be linked with sickness absence records, an informed consent form about the diagnoses of sick leaves, and a prepaid envelope were sent to all those physicians $(n=816)$, head nurses, and ward sisters $(n=542)$ who were employed by the hospitals both in 1997 and 1998. Head nurses and ward sisters, as the highest occupations in the nursing hierarchy in hospitals, served as a control group. The questionnaire assessed health, behavioural risks, work characteristics, and social circumstances. Approval of the ethics committee of the Finnish Institute of Occupational Health was obtained for the study.

\section{SURVEY MEASURES}

Measures of health were self rated health status (poor or average $v$ good), diagnosed chronic disease from a checklist of 14 diseases (yes $v$ 
no $)^{2}$ and the 12 item general health questionnaire (GHQ) that uses scoring to estimate caseness $(>3) .{ }^{12}$ Measures of health behaviours were smoking (current smoker $v$ non-smoker), alcohol consumption ${ }^{13}$ (none $0 \mathrm{~g}$; moderate consumption 1-260 g (men) and 1-210 g (women); high $>260 \mathrm{~g}$ (men) and $>210 \mathrm{~g}$ (women) of absolute alcohol a week), and physical activity ${ }^{214}$ (sedentary, leisure time physical activity of under half an hour of fast walking per week, $v$ not sedentary).

Indicators of work characteristics included feeling overloaded, overtime (average hours a week), on call (average days a month), job control, and teamwork. Overload was measured by the Harris scale ${ }^{15}$ (five items, coefficient $\alpha$ 0.76 ), job control by the relevant scale from the job content questionnaire ${ }^{16}$ (nine items, coefficient $\alpha$ 0.73), and teamwork - that is, the extent to which the members of a work unit share and accept common goals, interact with each other, and together develop performance, by the 14 item team climate inventory ${ }^{18}$ (coefficient $\alpha 0.89$; see appendix). These well validated scales have been successfully used in previous studies of healthcare personnel. ${ }^{15}$ 17 $^{19-22}$

Social circumstances were marital status (married $v$ not); negative life events during the previous 12 months (yes $v$ no on the basis of a checklist of 17 events and an open ended option $)^{2}$; perceived social support as assessed with the brief social support questionnaire ${ }^{23}$; and size of social network. ${ }^{2}$

SICKNESS ABSENCE

Employers' registers were used to assess sickness absence. These registers document each period of sick leave for every employee, giving the beginning and end dates of each spell. In accordance with the regulations, each sick leave certificate, irrespective of the place of issue, must be forwarded to these registers. In the case of short spells (1-3 days), employees inform their supervisor on the morning of the first day of absence and fill out their own certificate explaining their absence. For long spells (>3 days), a physician's examination on the 4th day of absence, at the latest, and a medical certificate covering the entire period of sickness absence are required. Maternity leave and absence due to caring for a sick child are not included in sickness absence.

The recording of attendance at work is reliable in the Finnish public sector including hospitals. ${ }^{1424}$ Employees are paid a full salary during their sick leave. Employers receive compensation from the Finnish Social Insurance Institution for loss of salary due to sick leave that lasts more than 8 days. To receive the full compensation to which they are entitled, employers are obligated to keep strict records of all sick leave.

Sickness absences of the participants between 1 January 1997 and 31 December 1998 were obtained from the registers. Overlapping, consecutive, or duplicated spells were merged. Sickness absences were divided into short and long spells of sickness absence.

Other variables measured were age, sex, and income.
STATISTICAL ANALYSIS

Differences in measures of health, behavioural risks, work, and social circumstances between male and female physicians and between female physicians and the female controls were tested by logistic regression analysis for dichotomous variables and by analysis of variance (ANOVA) for continuous variables. We determined the rates of short and long spells of sickness absence for occupational groups, men and women, and levels of health, behavioural risks, work characteristics, and social circumstances. We calculated the corresponding rate ratios and their $95 \%$ confidence intervals $(95 \%$ CIs) by Poisson regression analysis (the dispersion in short and long spells of sickness absence followed the assumptions for Poisson models). ${ }^{1424}$ Before entry into Poisson regression models, we standardised continuous variables-levels of income, work characteristics, social support, and size of social network-separately for male and female physicians and the control group. The relation between continuous variables and rates of absence was analysed by estimating rate ratios (SDs) between cut offs. We adjusted the rate ratios for age, sex, and income. We tested whether correlates of absences differed between male and female physicians and between female physicians and the female controls by applying interaction terms. ${ }^{25}$

For all statistical analyses we used the SAS program package. Poisson models were calculated with the GENMOD procedure. ${ }^{26}$

\section{Results}

In all, 447 (55\%) physicians (251 men and 196 women) and $483(89 \%)$ head nurses and ward sisters (17 men and 466 women) participated in the study. Men were excluded from the control group because of low numbers. The mean duration of follow up (from which vacations, sabbaticals, maternity leaves, and other absences were substracted) were 19.0 (SD 2.6) and 18.7 (SD 3.2) months for male and female physicians, respectively, and 20.2 (SD 1.3) months for the controls.

In physicians, response rate corresponded to those in earlier research. ${ }^{3-8} 27$ The respondents did not differ from the eligible population in age (44.8 $v 43.5$ years) and mean rate of short spells (38.0 237.9 spells/100 person-year) and long spells (20.2 v 20.2 spells/100 personyears). Female physicians were slightly overrepresented (44\% v 39\%). The control group was representative of the eligible head nurses and ward sisters (figures for the respondents and the eligible population were 49.6 versus 49.5 years of age, and 148.2 versus 154.9 short spells of sick leave and 56.6 versus 58.2 long spells of sick leave/100 person-years, respectively).

\section{COMPARISON BETWEEN PHYSICIANS AND}

CONTROLS

Compared with the control group of female head nurses and ward sisters, age adjusted absence rates for male and female physicians were significantly lower, the corresponding rate ratios for short spells being 0.40 (95\% CI 0.36 

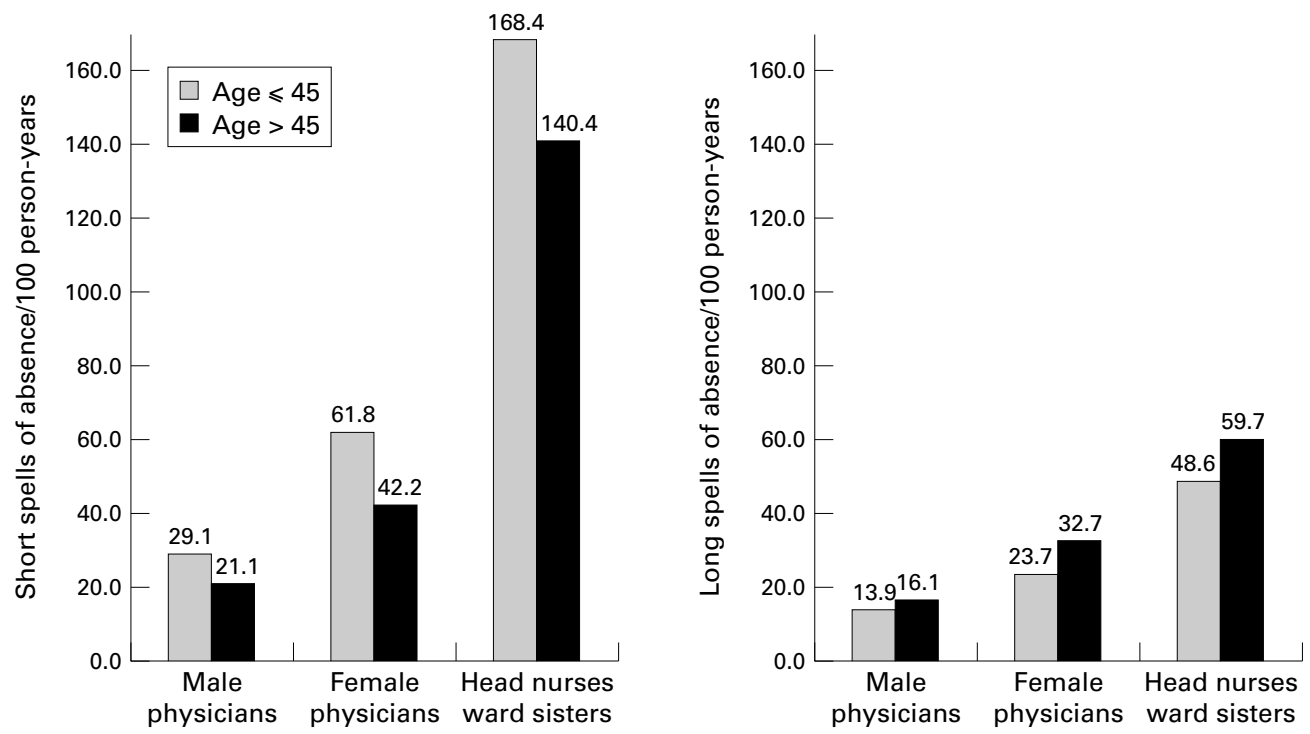

Figure 1 Rates of short (left) and long (right) spells of sickness absence in physicians and controls by age.

to 0.44$)$ and 0.35 (0.30 to 0.42$)$, respectively, and for long spells $0.52(0.46$ to 0.60$)$ and 0.53 (0.41 to 0.69$)$, respectively. For male physicians, age adjusted rates for short and long spells were 0.47 ( 0.36 to 0.62$)$ and $0.51(0.36$ to 0.73 ) times lower than for female physicians, respectively. Short spells of sickness absence were inversely related to age, but for long spells the direction of the association was opposite (fig 1).

As shown in table 1, there were no differences in self rated health, prevalence of diagnosed chronic illness, and psychiatric caseness between the groups. However, male physicians had higher alcohol consumption than female physicians and the female physicians had significantly higher consumption than controls. Except for greater hours of overtime among male physicians, work characteristics were similar for men and women physicians. Female physicians worked significantly more overtime, evaluated teamwork less favourably, and had smaller social networks than the controls.
FACTORS ASSOCIATED WITH SICKNESS ABSENCE As shown in tables 2 and 3, self rated health, diagnosed chronic illness, and psychiatric caseness were associated with sickness absence in physicians and controls, the relations to long spells being stronger than those to short spells. Self rated health and chronic illness were stronger correlates of long spells than any other variables under study. In physicians, none of the relations between health, behavioural risks and sickness absence was dependent on sex.

Feeling overloaded increased the risk of short spells in male physicians and the risk of short and long spells in the control group. It did not affect sickness absences among female physicians. Higher on call was associated with more long spells in male physicians but there was no association between on call and sickness absence in female physicians.

Low opportunities for job control and poor teamwork were stronger contributors of sickness absence among physicians than in the

Table 1 Descriptive statistics on potential determinants of sickness absence

\begin{tabular}{|c|c|c|c|c|c|c|c|c|c|c|c|}
\hline \multirow[b]{3}{*}{ Variable } & \multicolumn{7}{|l|}{ Doctors } & \multicolumn{4}{|l|}{ Controls } \\
\hline & \multicolumn{3}{|l|}{ Male } & \multicolumn{3}{|l|}{ Female } & \multirow{2}{*}{$\begin{array}{l}\text { Difference between } \\
\text { male and female } \\
\text { doctors }\end{array}$} & \multirow[b]{2}{*}{$\begin{array}{l}\text { Subjects } \\
(n)\end{array}$} & \multirow[b]{2}{*}{$\%$} & \multirow[b]{2}{*}{ Mean (SD) } & \multirow{2}{*}{$\begin{array}{l}\text { Difference between } \\
\text { female doctors and } \\
\text { controls }\end{array}$} \\
\hline & $\begin{array}{l}\text { Subjects } \\
(n)\end{array}$ & $\%$ & Mean (SD) & $\begin{array}{l}\text { Subjects } \\
\text { (n) }\end{array}$ & $\%$ & Mean $(S D)$ & & & & & \\
\hline \multicolumn{12}{|l|}{ Health and behavioural risks: ${ }^{\star}$} \\
\hline Self rated health (poor or average) & 248 & 11 & & 195 & 10 & & NS & 456 & 14 & & NS \\
\hline Diagnosed illness & 251 & 40 & & 196 & 33 & & NS & 466 & 49 & & NS \\
\hline Psychiatric morbidity (GHQ case) & 247 & 22 & & 193 & 27 & & NS & 454 & 24 & & NS \\
\hline Current smoker & 239 & 7 & & 190 & 7 & & NS & 443 & 10 & & NS \\
\hline $\begin{array}{l}\text { Alcohol consumption (g of absolute } \\
\text { alcohol/week) }\end{array}$ & 246 & & $195(201)$ & 194 & & $90(93)$ & $<0.001$ & 459 & & $61(70)$ & $<0.001$ \\
\hline Physical activity (sedentary) & 251 & 22 & & 196 & 21 & & NS & 466 & 21 & & NS \\
\hline \multicolumn{12}{|l|}{ Work characteristics: } \\
\hline Feeling overloaded & 249 & & $3.7(0.8)$ & 194 & & $3.7(0.8)$ & NS & 463 & & $3.8(0.8)$ & NS \\
\hline Overtime (h/week) & 246 & & $8.9(7.3)$ & 190 & & $6.5(7.4)$ & $<0.001$ & 434 & & $2.1(4.3)$ & $<0.001$ \\
\hline On call responsibility (days/month) & 251 & & $3.2(3.4)$ & 195 & & $3.3(3.0)$ & NS & - & & - & - \\
\hline Job control & 251 & & $4.1(0.5)$ & 195 & & $4.0(0.5)$ & NS & 464 & & $4.1(0.5)$ & $<0.01$ \\
\hline Teamwork & 251 & & $3.6(0.6)$ & 194 & & $3.5(0.5)$ & NS & 464 & & $3.8(0.5)$ & $<0.001$ \\
\hline \multicolumn{12}{|l|}{ Social circumstances: } \\
\hline Married & 249 & 88 & & 195 & 64 & & $<0.001$ & 463 & 71 & & NS \\
\hline Negative life events $(\geqslant 1)$ & 251 & 40 & & 196 & 43 & & NS & 466 & 43 & & NS \\
\hline Social support & 244 & & $10.0(5.4)$ & 194 & & $12.1(4.9)$ & $<0.001$ & 462 & & $12.9(5.4)$ & NS \\
\hline Social network (size) & 200 & & 19.7 (11.8) & 169 & & $18.5(12.5)$ & NS & 445 & & $21.9(12.8)$ & $<0.01$ \\
\hline
\end{tabular}

${ }^{\star}$ Tests of differences in health and behavioural risks are adjusted for age. 
Table 2 Rate ratios (95\% CIs) for short spells of sickness absence by levels of health, behavioural risks, and psychosocial factors (Poisson regression models adjusted for age, sex, and income)

\begin{tabular}{|c|c|c|}
\hline Variable $^{*}$ & $\begin{array}{l}\text { Doctors } \\
\text { Rate ratio (95\% CI) }\end{array}$ & $\begin{array}{l}\text { Controls } \\
\text { Rate ratio (95\% CI) }\end{array}$ \\
\hline \multicolumn{3}{|l|}{ Health and behavioural risks: } \\
\hline Self rated health (average or worse $v$ good) & 1.55 (1.08 to 2.23$)$ & $1.68(1.44$ to 1.95$)$ \\
\hline Diagnosed illness (yes $v$ no) & $1.45(1.12$ to 1.88$)$ & $1.21(1.08$ to 1.36$)$ \\
\hline Psychiatric morbidity (case $v$ not case) & $1.26(0.95$ to 1.66$)$ & $1.21(1.06$ to 1.39$)$ \\
\hline Smoking (smoker $v$ not smoker) & $1.06(0.64$ to 1.75$)$ & $0.89(0.72$ to 1.08$)$ \\
\hline \multirow{2}{*}{$\begin{array}{ll}\text { Alcohol consumption } & \text { (abstain } v \text { moderate) } \dagger \\
& \text { (high } v \text { moderate) }\end{array}$} & $0.57(0.23$ to 1.38$)$ & $1.40(1.17$ to 1.67$)$ \\
\hline & $0.87(0.60$ to 1.26$)$ & $0.81(0.61$ to 1.08$)$ \\
\hline Physical activity (sedentary $v$ not sedentary) & $0.88(0.57$ to 1.36$)$ & $0.84(0.72$ to 0.97$)$ \\
\hline \multicolumn{3}{|l|}{ Work characteristics: } \\
\hline \multicolumn{3}{|l|}{ Feeling overloaded (high $v$ low) $\ddagger$} \\
\hline Men & $1.76(1.12$ to 2.75$)$ & - \\
\hline Women & 1.07 (0.78 to 1.48$)$ & $1.15(1.02$ to 1.30$)$ \\
\hline Hours of overtime (high $v$ low) & $0.82(0.57$ to 1.06$)$ & $0.96(0.85$ to 1.09$)$ \\
\hline On call responsibility (high $v$ low) & $1.09(0.85$ to 1.39$)$ & - \\
\hline Job control (low $v$ high) $\dagger$ & $1.30(1.03$ to 1.67$)$ & $0.95(0.85$ to 1.07$)$ \\
\hline Teamwork (low $v$ high) & $1.15(0.89$ to 1.49$)$ & $1.08(0.98$ to 1.22$)$ \\
\hline \multicolumn{3}{|l|}{ Social circumstances: } \\
\hline \multicolumn{3}{|l|}{ Mariatal status (unmarried $v$ married) $\ddagger$} \\
\hline Men & $2.22(1.41$ to 3.51$)$ & - \\
\hline Women & $0.92(0.67$ to 1.27$)$ & $1.28(1.13$ to 1.44$)$ \\
\hline Negative life events (yes $v$ no) & $1.06(0.82$ to 1.36$)$ & $1.16(1.03$ to 1.30$)$ \\
\hline Social support (low $v$ high) & $1.01(0.78$ to 1.30$)$ & $1.02(0.91$ to 1.14$)$ \\
\hline Social network (small $v$ large) & $0.96(0.74$ to 1.27$)$ & $1.05(0.93$ to 1.18$)$ \\
\hline
\end{tabular}

${ }^{\star}$ Moderate alcohol consumption 1-260 g of absolute alcohol/week for men and 1-210 g for women. Sedentary lifestyle refers to physical activity corresponding to under half an hour of fast walking/week. Cut off points for low and high levels of work characteristics, social support, and social network were $-1 \mathrm{SD}$ and $+1 \mathrm{SD}$, respectively. $\mathrm{tp}<0.05$, difference in rate ratios between female doctors and controls. $\neq \mathrm{p}<0.05$, difference in rate ratios between male and female doctors.

Table 3 Rate ratios (95\% CIs) for long spells of sickness absence by levels of health, behavioural risks, and psychosocial factors (Poisson regression models adjusted for age, sex, and income)

\begin{tabular}{|c|c|c|}
\hline Variable & $\begin{array}{l}\text { Doctors } \\
\text { Rate ratio }(95 \% \text { CI) }\end{array}$ & $\begin{array}{l}\text { Controls } \\
\text { Rate ratio }(95 \% \text { CI) }\end{array}$ \\
\hline \multicolumn{3}{|l|}{ Health and behavioural risks: } \\
\hline Self rated health (average or worse $v$ good) & $2.74(1.84$ to 4.10$)$ & 2.15 (1.72 to 2.68$)$ \\
\hline Diagnosed illness (yes $v$ no) & $2.03(1.45$ to 2.86$)$ & $1.56(1.28$ to 1.90$)$ \\
\hline Psychiatric morbidity (case $v$ not case) & $1.79(1.26$ to 2.54$)$ & $1.55(1.26$ to 1.89$)$ \\
\hline Smoking (smoker $v$ not smoker) & $1.01(0.53$ to 1.92$)$ & $1.09(0.80$ to 1.47$)$ \\
\hline Alcohol consumption (abstain $v$ moderate) & $0.63(0.20$ to 1.99$)$ & $1.18(0.87$ to 1.61$)$ \\
\hline (high $v$ moderate) & $1.04(0.67$ to 1.62$)$ & $1.55(1.11$ to 2.18$)$ \\
\hline Physical activity (sedentary $v$ not sedentary) & $0.96(0.70$ to 1.43$)$ & $0.84(0.72$ to 0.97$)$ \\
\hline \multicolumn{3}{|l|}{ Work characteristics: } \\
\hline Feeling overloaded (high $v$ low) & $0.90(0.64$ to 1.26$)$ & $1.25(1.03$ to 1.52$)$ \\
\hline Hours of overtime (high $v$ low) & $1.01(0.71$ to 1.43$)$ & $0.96(0.79$ to 1.18$)$ \\
\hline \multicolumn{3}{|l|}{ On call responsibility (high $v$ low) $\dagger$} \\
\hline Men & $1.71(1.22$ to 2.39$)$ & \\
\hline Women & $0.65(0.38$ to 1.09$)$ & - \\
\hline Job control (low $v$ high) & $1.55(1.13$ to 2.13$)$ & $1.09(0.90$ to 1.31$)$ \\
\hline Teamwork (low $v$ high) $\ddagger$ & $1.80(1.30$ to 2.97$)$ & $0.98(0.80$ to 1.16$)$ \\
\hline \multicolumn{3}{|l|}{ Social circumstances: } \\
\hline Mariatal status (unmarried $v$ married) & $1.28(0.88$ to 1.88$)$ & $1.40(1.16$ to 1.71$)$ \\
\hline Negative life events (yes $v$ no) & $1.25(0.89$ to 1.77$)$ & $1.05(0.86$ to 1.27$)$ \\
\hline Social support (low $v$ high) & $1.08(0.76$ to 1.55$)$ & $1.06(0.88$ to 1.28$)$ \\
\hline Social network (small $v$ large) & $1.15(0.78$ to 1.68$)$ & $1.09(0.90$ to 1.33$)$ \\
\hline
\end{tabular}

${ }^{\star}$ Moderate alcohol consumption 1-260 g of absolute alcohol/week for men and 1-210 g for women. Sedentary lifestyle refers to physical activity corresponding to under half an hour of fast walking/week. Cut off points for low and high levels of work characteristics, social support, and social network were $-1 \mathrm{SD}$ and $+1 \mathrm{SD}$, respectively.

$\mathrm{tp}<0.05$, difference in rate ratios between male and female doctors.

$\ddagger \mathrm{p}<0.05$, difference in rate ratios between female doctors and controls.

control group. Problems in teamwork explained long absence spells in physicians more than any other work characteristic. A feeling of being overloaded was the strongest work related predictor of sickness absence among the controls.

Being married related to decreased sickness absence in male physicians and in the controls. In female physicians, marital status was not associated with sickness absence.

\section{Discussion}

This is the first study of hospital physicians to show the associations between recorded sickness absence and factors across various life domains. We found that the sources of sickness absence in hospital physicians cannot be explained only by the traditional focus on a person's health, overload, and job control but rather by problems in teamworking.

The present results confirm that absence rate for physicians is low; male and female doctors took one third to a half of the sick leave of nursing management, and the difference is even greater compared with the rates reported for other occupations in previous studies. ${ }^{28}$ Unlike in nurses, ${ }^{10}$ absence rates for nursing management (head nurses and ward sisters) were not high. In agreement with studies reporting sex differences in sickness absence across a wide variety of occupations, lower rates were found in male than in female physicians. ${ }^{28}$ 
Morbidity in hospital physicians did not differ from that in nursing management. As in other studies of physicians, ${ }^{6}$ the prevalence of psychiatric morbidity in our sample was $4 \%-9 \%$ higher than that found among the general population. In physicians and nursing management, morbidity and psychiatric caseness were the main determinants of sickness absence. However, the threshold for nonattendance seems to be higher for physicians than nursing management judging by the difference in rates of absence. This implies that long term absences is an indicator of more serious health problems in physicians than in nursing management. Research suggests that physicians tend to work through illness leading to a risk of impaired quality of care. ${ }^{5} \mathrm{~A}$ questionnaire survey indicated that almost $90 \%$ of physicians had worked even when they felt too unwell to carry out their duties to the best of their ability. ${ }^{4}$ This is unlikely to benefit either the physicians or their patients.

Behavioural risks in physicians were small with the exception that $35 \%$ of male doctors were high consumers of alcohol according to the criteria of Rimm et al for alcohol intake, ${ }^{29} \mathrm{a}$ finding in line with increased mortality from cirrhosis of the liver in this group. ${ }^{30}$ We found that physicians with high alcohol consumption did not take any more sick leave than other physicians. For this and other reasons, alcohol and drug misuse among physicians can be a threat to patients. ${ }^{31}$

In male doctors, overload increased sickness absence, whereas being married decreased it. After health outcomes, these two factors were the strongest predictors of sickness absence in nursing management. However, overload and marital status were not associated with sickness absence in female physicians, implying that they may be particularly reluctant to use absence as a coping method, and may benefit less from buffering social circumstances. Both these factors may reflect higher psychosocial vulnerability in women physicians, a hypothesis supported also by their higher depression scores. $^{32}$

A common pattern for responding to growing demands in hospitals has been increased multiprofessional teamwork. Our data show that absence of physicians should be examined in the context of teams-how often team members meet together and to what extent they have clear team and individual goals, value each other's diverse skills, and allocate joint efforts to develop performance. Physicians reported more problems with teamwork than the nursing management, but teamwork may have slightly different meanings for these two occupational groups. Doctors, who carry the main responsibility for diagnosis and treatment, were also significantly more affected by teamwork: after health outcomes, poor teamwork made the strongest contribution to long term absence of physicians, exceeding that related to overload and low perceived control. Previous research suggests that membership of a well functioning team reduces stress levels, ${ }^{33}$ and that problems experienced in collaboration at work predict suicide in physicians. $^{34}$ We found that effects of teamwork were greater on long spells of sickness absence than on short spells suggesting that poor teamworking has both an organisational and an individual cost. Long spells are a more accurate measure of health than short spells which may also reflect voluntary absenteeism.

The traditional focus on a person's health, overload, and job control in explaining absence has been an important first step, but the results of this study suggest broadening the view to the functioning of work teams. Such a perspective may not only increase our understanding of the determinants of sickness absence but may also assist efforts to promote health and wellbeing among physicians. After the introduction of commercial pressures into health care, significant reductions in workload may not be as achievable nor as effective as the development of teams and team leaders.

This study was supported by the Academy of Finland (project no 44968), Finnish Work Environment Fund (project no 97316), and the hospitals in districts of Varsinais-Suomi, Kanta-Häme and Vaasa, Finland. JEF was supported by the the preparation of this paper.

\section{Appendix: Work related scales}

In the overload scale the respondents were requested to rate stressors at their work along a five point Likert-type scale ranging from $1=$ very seldom causes pressure to $5=$ very often causes pressure. Stressors were:

- Time pressures and deadlines

- I have too little time in which to do what is expected of me

- The demands of others for my time at work are in conflict

- Work overload

- I spend my time "fighting fires" rather than working to a plan.

The scale of job control comprises the following nine items:

- My job allows me to make a lot of decisions on my own

- I have a lot of say about what happens on my job

- On my job, I have very little freedom to decide how I do my work (reversed scored)

- My job requires me to be creative

- My job involves a lot of repetitive work (reversed scored)

- My job requires a high level of skill

- My job requires that I learn new things

- I get to do a variety of different things on my job

- I have an opportunity to develop my own special abilities.

Responses were given along a five point Likert-type scale ranging from $1=$ strongly disagree to $5=$ strongly agree.

The teamwork scale comprises the following 14 items:

- How far are you in agreement with the objectives of your work unit?

- To what extent do you think objectives of your work unit are clearly understood by other members of the work unit?

- To what extent do you think objectives of your work unit can actually be achieved?

- How worthwhile do you think these objectives are to the organization?

- We have a "we are together" attitude

- People keep each other informed about work related issues in the work unit

- People feel understood and accepted by each other

- There are real attempts to share information throughout the work unit

- Are members of your work unit prepared to question the basis of what the work unit is doing? 
- Does the work unit critically appraise potential weaknesses in what it is doing to achieve the best possible outcome?

- Do members of the work unit build on each other's ideas to achieve the best possible outcome?

- People in this work unit are always searching for fresh, new ways of looking at problems

- In this work unit we take the time needed to develop new ideas

- People in the work unit cooperate to help develop and apply new ideas

- Responses for the items were given on five point Likert-type scales (eg, 1=strongly disagree to $5=$ strongly agree).

1 North F, Syme SL, Feeney A, et al. Psychosocial work environment and sickness absence among British civil servants: 40 .

2 Kivimäki M, Vahtera J, Thomson J, et al. Psychosocial factors predicting employee sickness absence during factors predicting employee sickness absence
economic decline. F Appl Psychol 1997;82:858-72.

3 Chambers R, Belcher J. Comparison of the health and lifestyle of general practitioners and teachers. Br f Gen Pract style of general p

4 McKevitt C, Morgan M, Dundas R, et al. Sickness absence and working through illness: a comparison of two professional groups. F Public Health Med 1997;19:295-300.

5 Waldron HA. Sickness in the medical profession. Ann Occup Hyg 1996;40:391-96.

6 Ramirez AJ, Graham J, Richards MA, et al. Mental health of hospital consultants: the effects of stress and satisfaction at work. Lancet 1996;347:724-8.

7 Deckard G, Meterko M, Field D. Physician burnout: an examination of personal, professional and organizational relationships. Med Care 1994;32:745-54.

8 Johnson JV, Hall EM, Ford DE, et al. The psychosocial work environment of physicians: the impact of demands and resources on job dissatisfaction and psychiatric distress in a longitudinal study of John Hopkins Medical School graduates. F Occup Environ Med 1995;37:1151-59.

ates. F Occup Environ Med 1995;37:1151-59.
9 Firth-Cozens J, Moss F. Hours, sleep, teamwork, and stress Firth-Cozens J, Moss F. Hours, sleep,
[editorial]. BMF 1998;317:1335-6.

10 Williams S, Michie S, Pattani S. Improving the health of the NHS workforce: report of the partnership on the health of the NHS workforce. London: Nuffield trust, 1998.

11 Firth-Cozens J. The psychological problems of doctors. In Firth-Cozens J, Payne R, eds. Stress in health professionals. psychological and organizational causes and intervention. Chichester, UK: Wiley, 1999:299-322.

12 Goldberg D, Williams P. A user's guide to the general health questionnaire. Berkshire, UK: NFER-Nelson, 1988.

13 Kaprio J, Koskenvuo M, Langinvainio H, et al. Genetic influences on use and abuse of alcohol: a study of 5638 adult Finnish twin brothers. Alcohol Clin Exp Res 1987;11: 349-56.

14 Kivimäki M, Vahtera J, Pentti J, et al. Factors underlying the effect of organisational downsizing on health of employees: effect of organisational downsizing on health of em
longitudinal cohort study. $B M \mathcal{F} 2000 ; 320: 971-5$.
15 Harris PE. The nurse stress index. Work Stress 1989;3:33545.

16 Withdrawn

17 Kivimäki $M$, Elovainio $M$. A short version of the team climate inventory: development and psychometric properties. Fournal of Occupational and Organizational Psychology 1999;72:241-6.

18 Anderson N, West MA. The team climate inventory. Windsor, UK: Berks ASE, 1994.

19 Cooper CL, Mitchell S. Nurses under stress: a reliability and validity study of the NSI. Stress Med 1990;6:21-4.

20 Kivimäki M, Lindström K. Effects of private self consciousness and control on the occupational stress-strain relationship. Stress Med 1995;11:7-16.

21 Elovainio M, Mäkelä M, Sinervo T, et al. Effects of job characteristics, team climate, and attitudes on the use of clinical guidelines. Scand 7 Public Health 1999;28:117-22.

22 Cheng Y, Kawachi I, Coakley EH, et al. Association between psychosocial work characteristics and health functioning in American women: prospective study. BMF 2000;320:143226

23 Sarason IG, Sarason BR, Shearin EN, et al. A brief measure of social support: practical and theoretical implications. Fournal of Social and Personal Relations 1987;4:497-510.

24 Vahtera J, Kivimäki M, Pentti J. Effect of organisational downsizing on health of employees. Lancet 1997;350:11248 .

25 Cohen J, Cohen P. Applied multiple regression/correlation analysis for the behavioral sciences, 2nd ed. Hillsdale NJ: Erlbaum, 1983.

26 SAS. SAS technical report P-243, SAS/STAT software: the GENMOD procedure, release 6.09. Cary, NC: SAS Institute, 1993.

27 Asch DA, Christakis NA, Ubel PA. Conducting physician mail surveys on limited budget: a randomized trial comparing $\$ 2$ bill versus $\$ 5$ bill incentives. Med Care 1998;36:95-9.

28 Vahtera J, Virtanen P, Kivimäki M, et al. Workplace as an origin of health inequalities. F Epidemiol Community Health 1999;53:399-407.

29 Rimm EB, Williams P, Fisher K, et al. Moderate alcohol intake and lower risk of coronary heart disease: a meta-analysis of effects of lipids and haemostatis factors. BMF 1999;319:1523-8.

30 Office of Population Censuses and Surveys. Occupational mortality and decennial supplement 1979-80, 1982-83. London: The Stationery Office, 1986.

31 Fowlie DG. The misuse of alcohol and other drugs by doctors: a UK report and one region's response. Alcohol Alcoholism 1999;34:666-71.

32 Caplan R. Stress, anxiety and depression in hospital consultants, general practitioners and senior health managers. BMF 1994;309:1261-3.

33 Carter AJ, West MA. Sharing the burden: team work in health care setting. In: Firth-Cozens J, Payne R, eds. Stress in health professionals: psychological and organizational causes and interventions. Chichester, UK: Wiley, 1999:323-61.

34 Holmes VF, Rich CL. Suicide among physicians. In: Blumenthal SJ, Kupfer DJ, eds. Suicide over the life cycle: risk factors, assessment, and treatment of suicidal patients. Washington, DC: American Psychiatric Press, 1990:599-618.

\title{
Narrative Based Medicine, An Interdisciplinary Conference
}

\author{
Research, Narrative, and Practice
}

\author{
A two day conference-Monday 3rd and Tuesday 4th September 2001 \\ Homerton College, Cambridge, UK
}

\section{BMF Publishing Group}

For full details contact: BMA/BMJ Conference Unit, Tavistock Square, London, WC1H 9JP Tel: +44 (0)20 7383 6819; fax: +44 (0)207383 6663; email: clyders@bma.org.uk. www.quality.bmjpg.com 